\title{
Usefulness of Pirfenidone in Covid Lung: A Case Series
}

\author{
Abdul Basit Ibne Momen, Farhana Khan, Sadia Saber, Amrin Sultana, Rafa Faaria Alam, \\ Sheikh Golam Raihan, Mohammad Monower Hossain, and Md Tarek Alam
}

\section{ABSTRACT}

The year 2020 has been plagued by the COVID-19 pandemic that has resulted in an additional $1,800,000$ deaths worldwide. Many patients who recover from Covid-19 later present with shortness of breath and fibrosis of the lungs, while some take a long time to recover from the initial infection. A drug such as pirfenidone, which has been used for the treatment of idiopathic pulmonary fibrosis, could offer additional benefits by reverting pulmonary fibrotic damage. Here we describe a case series of five patients where addition of this drug showed marked improvement in symptoms and radiological findings. Apart from the efforts regarding understanding the pathophysiology of this new disease, we must also evaluate the proportion of patients that develop chronic lung disease due to fibrosis following COVID-19 recovery. Certainly, more attention should be given to new studies to determine the actual benefit of pirfenidone in patients with pulmonary fibrosis as a result of Covid-19 infection.

Keywords: COVID-19, Pirfenidone, Pulmonary Fibrosis.

\section{INTRODUCTION}

SARS-CoV-2 infection may be mild for most but for a few it has devastating consequences, starting from tissue hyper inflammation, fibrosis and scarring of the lungs, lung collapse, multi-organ dysfunction, and even death [1]. Until now, there are no proven antiviral drugs against SARS$\mathrm{CoV}-2$, so it is very vital to lower the aggressiveness of the viral infection [2]. SARS-CoV-2 infection is divided into three stages, in the first stage the patient being
Published Online: January 19, 2021

ISSN: 2593-8339

DOI: $10.24018 /$ ejmed.2021.3.1.670

\section{Abdul Basit Ibne Momen*}

Registrar, Department of Medicine, Bangladesh Medical College, Dhaka, Bangladesh.

(e-mail: abdulbasit17@gmail.com)

F. Khan

Senior Lecturer, Department of

Pharmacology, Ad-Din Women's Medical College, Dhaka, Bangladesh.

(e-mail: farhanakhan488@gmail.com)

S. Saber

Assistant Professor, Department of

Medicine, Bangladesh Medical College,

Dhaka, Bangladesh.

(e-mail: sadiasaber201477@gmail.com)

A. Sultana

Assistant Registrar, Department of

Medicine, Bangladesh Medical College,

Dhaka, Bangladesh.

(e-mail: amrinsultana2014@gmail.com)

R. F. Alam

Assistant Registrar, Department of

Medicine, Bangladesh Medical College,

Dhaka, Bangladesh.

(e-mail: rafa.alam27@gmail.com)

S. G. Raihan

Medical officer, Department of

Transfusion Medicine, Bangladesh

Medical College, Dhaka, Bangladesh.

(e-mail: raidenzero2008@ gmail.com)

M. M. Hossain

Medical officer, Department of Medicine,

Bangladesh Medical College, Dhaka,

Bangladesh.

(e-mail: mhhossain44@gmail.com)

M. T. Alam

Professor and Head, Department of

Medicine, Bangladesh Medical College,

Dhaka, Bangladesh.

(e-mail: mtarekalam16@gmail.com)

*Corresponding Author

asymptomatic or barely symptomatic with slight sore throat, the second and third stages include inflammation of the lungs and respiratory distress syndrome respectively [3]. Many patients who seem to recover from mild COVID-19 later present with shortness of breath and fibrosis of the lungs, while some take a long time to recover from the initial infection. The second and third stages are the most crucial; in order to prevent formation of fibrotic tissue there needs to be a well-timed immunomodulatory and antiinflammatory treatment. A drug that is currently indicated 
for pulmonary fibrosis, such as pirfenidone, could offer great additional benefits both during viral infection and in the recovery phase with remaining pulmonary fibrotic damage [4].

\section{CASE REPORT}

\section{A. Case 1}

A 46-year-old Covid-19 positive man was admitted with the complaints of fever and malaise for 12 days and severe difficulty in breathing for 7-8 days. On admission his saturation was $90 \%$ and he was immediately started on supplemental oxygen therapy and standard of care. His condition improved but he remained short of breath while performing daily activities and his oxygen saturation remained at $94 \%$ and his chest X-ray (Fig. 1) showed interstitial involvement, which did not resolve even after 20 days of supportive care. After that he was put on pirfenidone $267 \mathrm{mg} 1+0+1$. After 2 months his symptoms improved, oxygen saturation was around $97 \%$ and his X-ray (Fig. 2) had clearly improved.

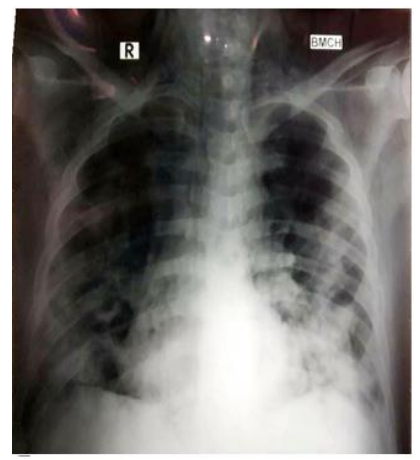

Fig. 1. Patient 1, before antifibrotic.

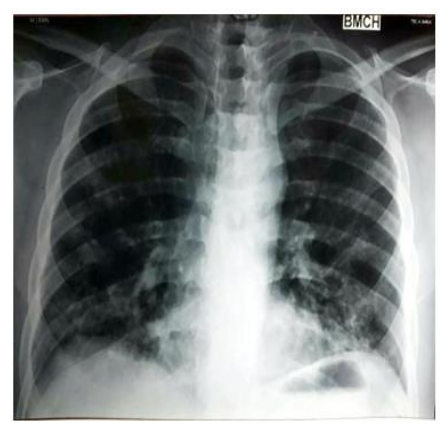

Fig. 2. Patient 1, after anti-fibrotic.

\section{B. Case 2}

A 40-year-old COVID-19 positive man presented with low grade fever, cough, and severe breathlessness; he had an oxygen saturation of $94 \%$ with $10 \mathrm{~L}$ supplemental oxygen on admission. As with Patient 1, patient 2 also improved with standard care but at a much slower rate and his X-rays showed persistent interstitial infiltrates (Fig. 3). He was also started on pirfenidone $267 \mathrm{mg} 1+0+1$. After 40 days the patient had improved enough to be discharged and his X-ray (Fig. 4) the day before discharge was improved as well.

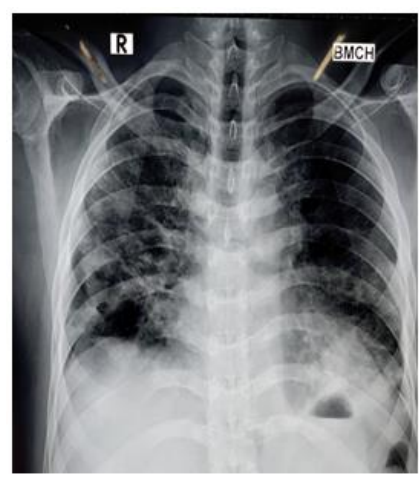

Fig. 3. Patient 2, before anti-fibrotic.

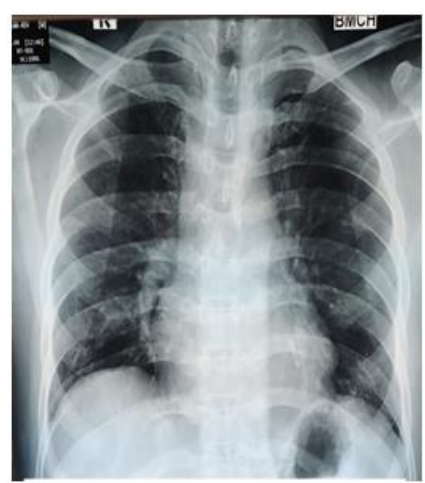

Fig. 4. Patient 2, after anti-fibrotic.

\section{Case 3}

A 60-year-old COVID-19 positive man presented with severe breathlessness and high fever; his condition was severe enough to warrant admission to ICU. He was put on high flow oxygen and the standard treatment started. Given the severity of the patient's lung involvement (Fig. 5) pirfenidone was started at a dose of $267 \mathrm{mg} 1+1+1$. After 45 days the patient was fit for discharge, considering his overall health and improvement of chest X-ray (Fig. 6).

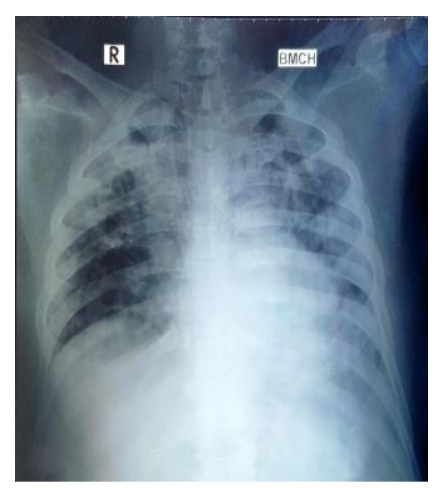

Fig. 5. Patient 3, before antifibrotic.

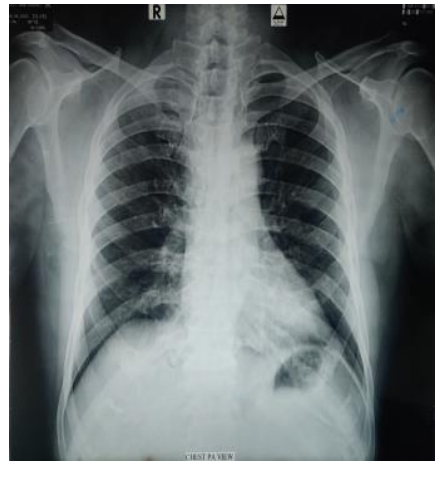

Fig. 6. Patient 3, after antifibrotic.

\section{Case 4}

A 48-year-old Covid-19 positive man was admitted to the hospital feeling shortness of breath after exertion. He said that he had cough and a mild fever of 2 days and was given standard of care. On the $14^{\text {th }}$ day he became negative and was discharged. Soon after discharge he started having increasing shortness of breath, severe dry cough and low oxygen saturation level. A CT scan of the chest (Fig. 7) revealed bilateral ground glass opacities indicating pulmonary fibrosis. The patient was started on pirfenidone $267 \mathrm{mg} 1+1+1$. And after 7 days the dose was increased to $2+2+2$. The repeat CT scan after 6 weeks (Fig. 8) showed significant radiological improvement.

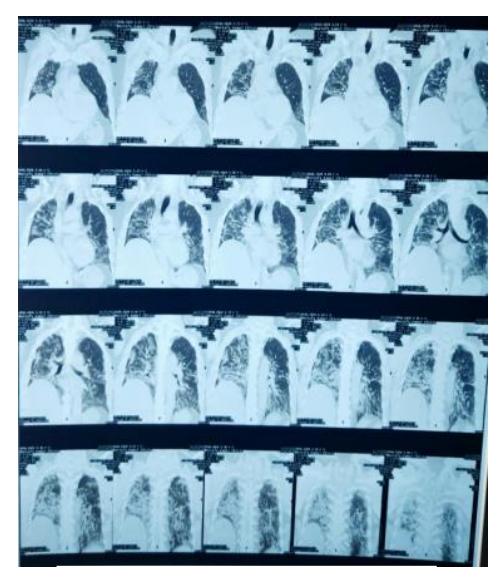

Fig. 7. Patient 4, before antifibrotic.

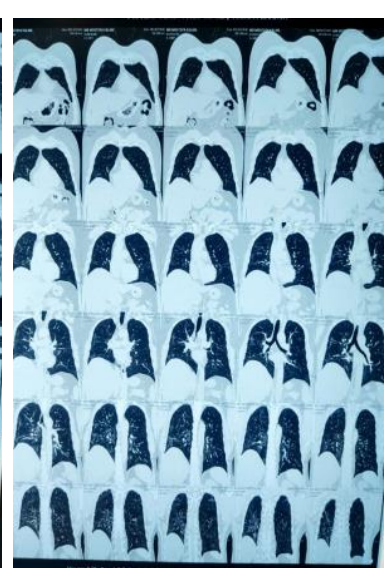

Fig. 8. Patient 4, after antifibrotic.

\section{E. Case 5}

A 53-year-old man with severe Covid-19 was admitted to the ICU and was on 60L of oxygen by high flow nasal cannula. CT chest (Fig. 9) showed more than $70 \%$ involvement bilaterally. He was started on pirfenidone 267 $\mathrm{mg} 1+1+1$, and then the dose was increased to $801 \mathrm{mg}$ 
$1+1+1$ and continued for 3 months. CT chest (Fig. 10) after 3 months showed significant improvement.

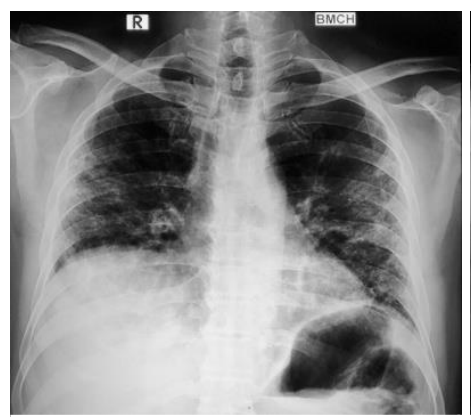

Fig. 9. Patient 5, before anti-fibrotic.

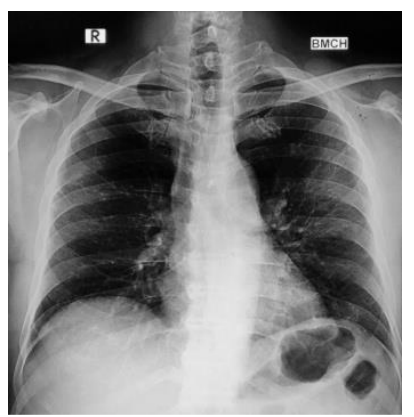

Fig. 10. Patient 5, after anti-fibrotic.

\section{DISCUSSION}

Pirfenidone was approved as an anti-fibrotic in China in December 2013 for the treatment of idiopathic pulmonary fibrosis (IPF) [5]. The reduction in the over expression of TGF- $\beta$, connective tissue growth factor (CTGF), plateletderived growth factors (PDGF), and tumour necrosis factor (TNF)- $\alpha$ in inflammatory diseases plays a key role in the anti-fibrotic activity of pirfenidone [6]. Like many patients with post covid-19 fibrosis the five patients mentioned above also developed pulmonary fibrosis after covid-19 which did not improved with standard care and necessitated the use of an anti-fibrotic such as pirfenidone. Addition of which showed marked improvement of both the patient's symptoms and improvement of the radiological finings.

Some other studies showed similar findings, likewise, highlighted the shared danger of Coronavirus and IPF, and referenced that the weight of lung fibrosis following COVID-19 is probably going to be high; they presumed that given the size of the pandemic, the worldwide weight of fibrotic lung sickness will presumably increase impressively. They additionally recommended a remedy like Pirfenidone and nintedanib as an anti-fibrotic treatment [7].

Another study shows an anti-fibrotic drug like pirfenidone as monotherapy or together with antiinflammatory drugs will be (acting early, at the proper doses and at the proper time) therapeutically effective to avoid serious complications during virus infection. The identical approach can even be effective as post-infection therapy in patients with residual pulmonary fibrotic damage [8].

It can be suggested that pirfenidone cause reduction of lung injury based on a published data which shows that pirfenidone decreases Lipo-polysaccharide (LPS) -induced lung injury and subsequent fibrosis by suppressing NLRP3 inflammatory reaction [9].

Moreover, there's evidence of potential use of pirfenidone, azithromycin and prednisolone within the management of pulmonary fibrosis post-H1N1 ARDS, supported data from a case report of three patients (young males aged between 40-59 years) [10].

\section{CONCLUSION}

We acknowledge the limitations of these case reports and recognize that additional studies are needed to determine the actual benefit from pirfenidone. Finally, only a welldesigned double-blind randomized controlled test is the accepted technique to analyze this hypothesis.

\section{REFERENCES}

[1] Li YC, Bai WZ, Hashikawa T. The neuroinvasive potential of SARS-CoV2 may play a role in the respiratory failure of COVID-19 patients. Journal of medical virology. 2020 Jun;92(6):552-5. Zhu N, Zhang D, Wang W, Li X, Yang B, Song J, Zhao X, Huang B, Shi W, Lu R, Niu P, Zhan F, Ma X, Wang D, Xu W, Wu G, Gao GF, Tan W, China Novel Coronavirus Investigating and Research Team (2020) A novel coronavirus from patients with pneumonia in China, 2019. N Engl J Med 382:727-733.

[2] Guan WJ, Ni ZY, Hu Y, Liang WH, Ou CQ, He JX, Liu L, Shan H, Lei CL, Hui DSC, du B, Li LJ, Zeng G, Yuen KY, Chen RC, Tang CL, Wang T, Chen PY, Xiang J, Li SY, Wang JL, Liang ZJ, Peng YX, Wei L, Liu Y, Hu YH, Peng P, Wang JM, Liu JY, Chen Z, Li G, Zheng ZJ, Qiu SQ, Luo J, Ye CJ, Zhu SY, Zhong NS, China Medical Treatment Expert Group for Covid-19 (2020) Clinical characteristics of coronavirus disease 2019 in China. N Engl J Med 382:1708-1720

[3] King CS, Nathan SD. Idiopathic pulmonary fibrosis: effects and optimal management of comorbidities. The Lancet Respiratory Medicine. 2017 Jan 1;5(1):72-84.

[4] Maher TM, Corte TJ, Fischer A, Kreuter M, Lederer DJ, MolinaMolina M, Axmann J, Kirchgaessler KU, Samara K, Gilberg F, Cottin V. Pirfenidone in patients with unclassifiable progressive fibrosing interstitial lung disease: a double-blind, randomised, placebocontrolled, phase 2 trial. The Lancet Respiratory Medicine. 2020 Feb $1 ; 8(2): 147-57$.

[5] Yang Y, Ye Y, Lin X, Wu K, Yu M. Inhibition of pirfenidone on TGF-beta2 induced proliferation, migration and epithlialmesenchymal transition of human lens epithelial cells line SRA01/04. PloS one. 2013 Feb 21;8(2): e56837.

[6] Lancaster LH, de Andrade JA, Zibrak JD, Padilla ML, Albera C, Nathan SD, Wijsenbeek MS, Stauffer JL, Kirchgaessler KU, Costabel U. Pirfenidone safety and adverse event management in idiopathic pulmonary fibrosis. European respiratory review. 2017 Dec 31;26(146).

[7] George PM, Wells AU, Jenkins RG. Pulmonary fibrosis and COVID19: the potential role for antifibrotic therapy. The Lancet Respiratory Medicine. 2020 May 15.

[8] Ferrara F, Granata G, Pelliccia C, La Porta R, Vitiello A. The added value of pirfenidone to fight inflammation and fibrotic state induced by SARS-CoV-2. European Journal of Clinical Pharmacology. 2020 Nov;76(11):1615-8.

[9] Li Y, Li H, Liu S, Pan P, Su X, Tan H, Wu D, Zhang L, Song C, Dai M, Li Q. Pirfenidone ameliorates lipopolysaccharide-induced pulmonary inflammation and fibrosis by blocking NLRP3 inflammasome activation. Molecular immunology. 2018 Jul 1; 99:134-44.

[10] Saha A, Vaidya PJ, Chavhan VB, Achlerkar A, Leuppi JD, Chhajed PN. Combined pirfenidone, azithromycin and prednisolone in postH1N1 ARDS pulmonary fibrosis. Sarcoidosis, Vasculitis, and Diffuse Lung Diseases. 2018;35(1):85. 